\title{
VALUE ORIENTATIONS, EMOTIONAL INTELLIGENCE AND INTERNATIONAL PEDAGOGICAL INNOVATIONS
}

\author{
Michael Alexander Radin \\ Rochester Institute of Technology School of Mathematical Sciences, U.S.A. \\ Natalia Shlat \\ Pskov State University, Russian Federation
}

\begin{abstract}
The primary goal of this paper is to portray how the value orientations and priorities can direct us to new pedagogical cores and innovations and leadership. First of all, we will examine how the students' value orientations and priorities become a pertinent factor in conceiving new teaching practices that enhance the amiable learning atmosphere and guides us to new ideas and leadership. Second of all, we will focus on how value orientations and priorities expand our current knowledge and comprehension of the students' learning styles and demands and gravitate teachers and students to the concept of emotional intelligence; this then leads students and teachers to new international and interdisciplinary environment(s) and to new teaching and learning practices. In addition, our aim is to address the students' value orientations and priorities and apply them to steer us to design new learning environment(s) and to the transformational and primal leaderships. Furthermore, our intent is to render how value orientations guide to the emotional intelligence, which then directs to new practices, ideas and innovations. Moreover, we will share specific examples of successful pedagogical innovations that lead to the emotional intelligence and were guided by the students' value orientations and priorities. Throughout this paper we will remit the following vital question: how do we link the value orientations together with the emotional intelligence and the transformational and primal leaderships?
\end{abstract}

Keywords: value orientations, emotional intelligence, pedagogical innovations, transformational leadership.

\section{Introduction}

Emotional Intelligence is defined as the ability to describe and understand others' emotions and to handle interpersonal relationships and conflicts smoothly and empathetically. In addition, the Emotional Intelligence, Emotional Leadership, Emotional Quotient and the Emotional Intelligence Quotient are the capacity of individuals to recognize their own emotions and others' emotions, discern between different feelings and comprehend them appropriately. Applying the emotional intelligence and the information that directs to rational thinking and to managing and adjusting the emotions in order to acclimate to the 
circumstance(s) to achieve the goals (Daniel Goldman). Emotional intelligence is an essential source that directs to critical thinking, flexibility, tolerance, effective decision making, leadership and innovations (Epstein, 1998).

Throughout the paper we will remit the following questions: why are the Transformational and Primal Leaderships pertinent concepts in preserving the positive learning environment and inspiring students to learn? Why are the students' value orientations essential for future boosts and innovations and how to assess them accurately and precisely for further improvements (Hussain \& Khan, 2016)? In addition, how to apply the value orientations and the emotional intelligence to design new innovations that correspond to the Primal Leadership while encouraging and enhancing critical thinking (Epstein, 1998)? What impacts and differences do the new practices and innovations produce and how will the students and participants benefit from them?

First of all, our goal of this paper is to render how the students' and colleagues' feedback becomes an essential tool that guides us to the students' value orientations and how to link value orientations together with the emotional intelligence and the transformational and primal leaderships to increase the students' participation and their learning inspiration. Second of all, our aims are to then apply the emotional intelligence and the two leaderships to design new teaching themes, practices and innovations that enhance the learning environment, persuade students to learn and retain the students' eagerness and support.

Also, our paper's aim is to accurately apply the students' and colleagues' feedback as guides to emotional intelligence, which then leads to tweaking the ambience of the mini-courses and seminars with the introduction of new teaching themes, practices and innovations that enhances the students' interest and participation. In addition, our objectives are to depict how feedback, leadership, and the students' value orientations blend together when designing new teaching practices to boost the students' curiosity and partaking.

Furthermore, the paper's intents are to emphasize how vital it is to be flexible to the students' value orientations; value orientations are a vital guide and tool to designing and implementing new themes and pilots that direct us to new teaching practices and retain the quality leadership (Corley, 2010). In fact, we will apply the data and feedback during the last 10 years by using the students' and participants' evaluations while teaching the mini-courses, conducting the seminars and the presentations and workshops at conferences. Finally, our intents are to emphasize how deciphering the students' and participants' feedback directs to value orientations, which then stimulate new teaching themes, practices and hence guide to the emotional intelligence and the two leaderships while designing and implementing new ideas; in particular, creating a positive and amiable learning atmosphere that inspires the students to learn. We will thoroughly 
analyse the data and feedback from the mini-courses and seminars conducted at Riga Technical University, Liepaja University and the Rezekne Technical Academy (RTA).

\section{Students’ Value Orientations and New Pedagogical Practices}

Flexibility to the students' feedback and implementing new practices from the students' evaluations is the first vital step to improving the students' and participants' engagement and in the development of new pedagogical practices (Orlova \& Radin, 2019). Implementation of the students’ comments and concerns enhances the Transformational and the Sustainability Leaderships, influences positive changes and provides long-term learning (Orlova \& Radin, 2018). The students' feedback also provide several additional beneficial guides that lead to the comprehension of the students' value orientations. The students' value orientations change analogously with the new political and cultural changes, educational reforms, technological advances and with the current international influences. On one hand it becomes a challenge to keep up with the students' value orientations. On the other hand, it is an art and science to design new themes, practices and innovations to address the students' learning styles and needs in order to retain their curiosity and engagement. Furthermore, it becomes a bigger challenge to render the concept of emotional intelligence to the students while designing and implementing new pedagogical practices. However, conveying the emotional intelligence is essential in order to encourage critical thinking together with creativity and leadership to the students (Curran, Morris, Farrell, \& Woods, 2007).

For instance, Michael has been teaching the "Introduction to Photography" hands-on course in Liepaja University for four years. In this course, each student is required to present his/her photographs at the beginning of each class and while the other students then have the opportunities to comment on each photograph by offering constructive critiques; in particular, what problems do they see and how to correct the problems to enhance the quality of the photographs. This teaching style rendered a positive learning atmosphere by encouraging critical thinking and innovations. The students recommended other students to take the course and the class enrolment gradually increased. This teaching style resembles the Transformational Leadership as it spread the effective teaching practice to other students. However, some students did express concerns that emphasized their value orientations. First of all, these students wanted the course to focus a bit more on the technical photography instead of just the principles of photographical composition. Second of all, the students also expressed interest in designing a course webpage on facebook that shares the photographs among the participants and to continue the communication after the course on facebook instead of 
communication by e-mail. This in fact mimics the new and more effective communication among the students; the students' value orientations lead to this new idea by suggesting to apply the current social networks to promote the course and the diversity of students' photographs. In addition, the students expressed interest in a tri-lingual course in English, Russian and Latvian. This has been a new trend in several international conferences hosted in Latvia.

Michael also conducts his annual "Risk Management Seminar" hosted by the Riga Technical University Department of Engineering Economics. The students really appreciated the special hands-on seminar that offers practical experiences in risk estimation by designing a specific risk matrix while addressing several daily related applications. Michael received very positive and supportive evaluations. On the other hand, analogous to the Introduction to Photography course, the participants from the Riga Fire Department expressed their concern that the seminar was focused too much on the design of the risk matrices. Instead of focusing on the construction of the risk matrices and how to apply them in the risk estimation, the Fire Department expressed future interest in the comparative cross-cultural seminar that compares the similarities and difference between the American and the Latvian Fire Departments and to include very unique historical cases of fire-fighting and the fire prevention techniques. They especially suggested to compare the similarities in differences in the equipment and the vehicles that are used. The participants offered to include more diversity of the fire-fighting techniques and preventions that deal with different materials, liquids and gases. These were very instrumental ideas for future seminars' themes that will attract more participants and foster a more dynamic engagement.

Furthermore, Michael leads his hands-on seminars on "Developing International \& Interdisciplinary Research Coalitions" for the graduate students hosted by the Riga Technical University Doctoral School. The seminar consists of two parts; part I focuses on developing an international and interdisciplinary collaboration and part II addresses the implementation. The first time Michael conducted this seminar in June 2017 and received very supportive evaluations. Now we will compare the students' evaluations and comments during the twoyear time span between the two seminars. The figure below renders the students' evaluations of the first pilot seminar conducted in June 2017:

Note that Figure 1 indicates the students' ratings of $91.2 \%$ in the topic coverage, $77.8 \%$ in the content's details, $86.6 \%$ as the narrative of the lecturer, $97.8 \%$ in the venue of the seminar, and $86.6 \%$ in the time of the seminar. In fact, the students felt that some of the ideas needed to be conveyed in more step by step details. The students also suggested to provide some practical insights that remit how to solve problems within the given deadlines and within the budgetary constraints. In addition, the students felt that more examples from personal experiences would have been beneficial by addressing factors such as how much 
time is dedicated to developing and implementing the ideas, what was the motivation and provide more "inside knowledge".

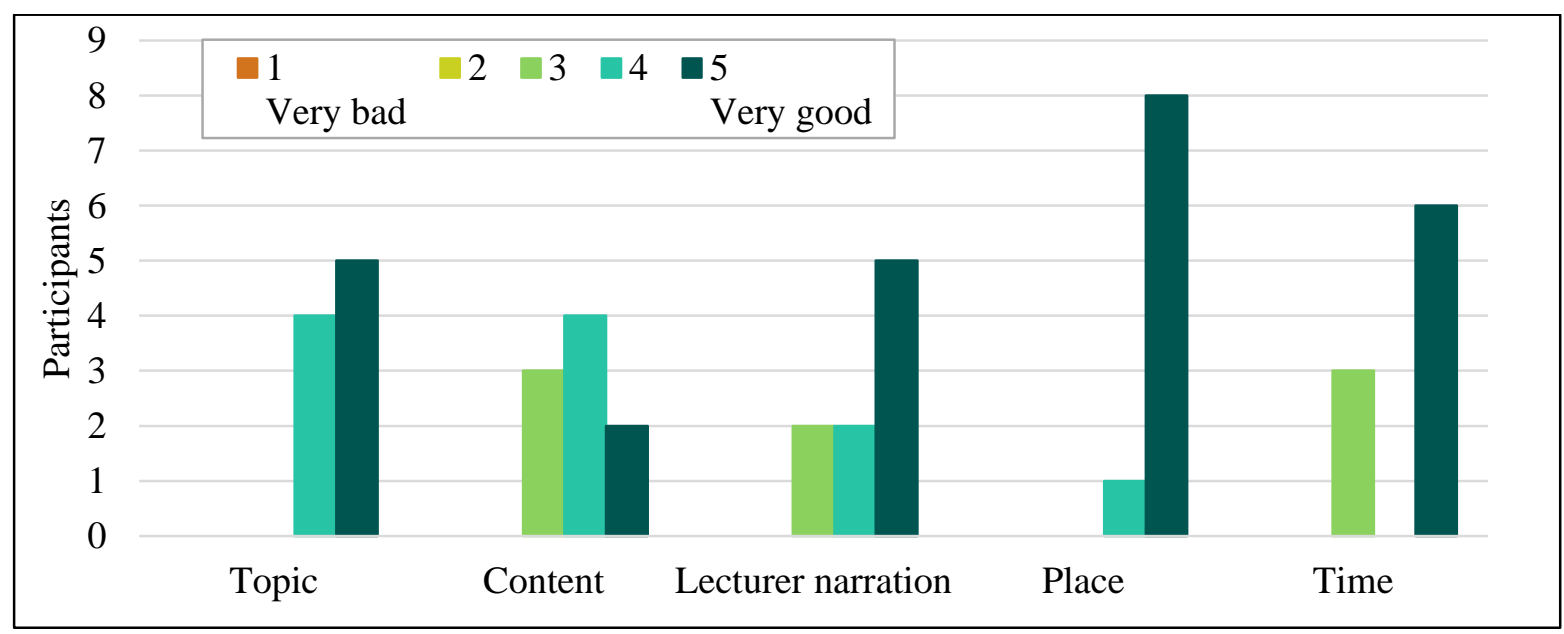

Figure 1 Students' seminar evaluations conducted in June 2017

After carefully analysing the students' comments and evaluations, based on the students' value orientations, Michael's intuition guided him to revise the seminar's topics by introducing more related and current topics that were not addressed during the first implementation and sharing more practical experiences that relate to the students' value orientations, needs and goals. In addition, by applying his intuition, Michael decided to comprise more class discussions that exposed the students to questions such as the understanding what are the limited resources and how to function effectively within the constraints and the limited resources. Figure 2 depicts the students' evaluations of the seminar conducted in June 2019.

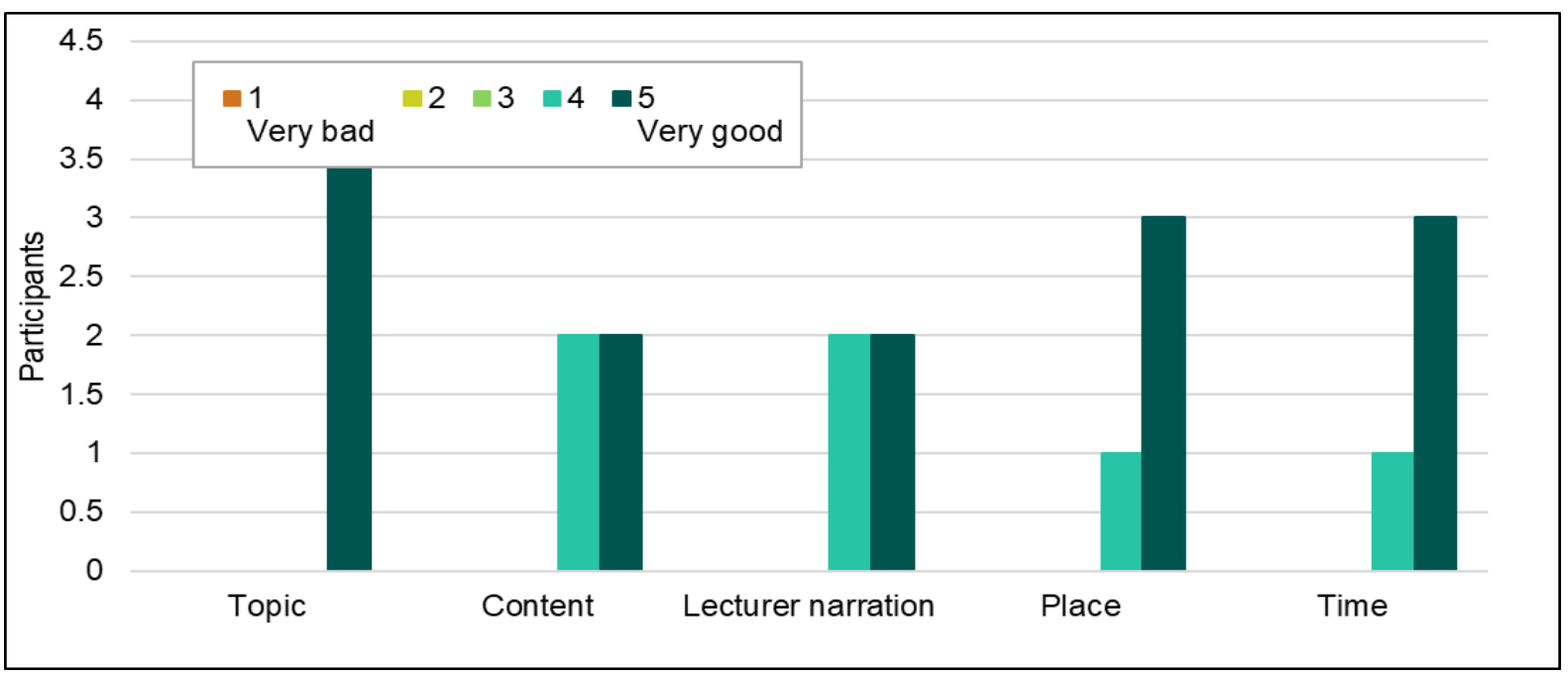

Figure 2 Students' seminar evaluations conducted in June 2019 
In comparison to Figure 1, Figure 2 emphasizes the students' ratings of $100 \%$ in the topic coverage, $90 \%$ in the content's details, $90 \%$ as the narrative of the lecturer, $97.5 \%$ in the venue of the seminar, and $97.5 \%$ in the time of the seminar. This is a significant improvement since the first time that the seminar was conducted. The students also wrote the following comments "It is interesting to learn from others' experiences, especially from a foreign lecturer”, "Thanks for the seminar and it is a pity that there were only two sessions". The seminar's performance substantially improved as Michael applied the emotional intelligence by following the students' value orientations' path that lead to the implementation of new principles.

\section{Emotional Intelligence, New Mini-courses and Seminars}

We can alternatively define emotional intelligence as the ability to interpret and assess others' emotions in order to make influential decisions that will guide to the effective primal leadership and new ideas. The domains of the Emotional Intelligence are outlined by the Gantt Chart, where the personal competence and the social competence are the primary domains; the self-awareness and the selfmanagement are the sub-domains of the personal competence and the socialawareness relationship management are the sub-domains of the social competence (Bourne, Hanna, Solomon, Smith, \& Sherwood, 2017). Emotional Intelligence is often interpreted as an emotional potential, emotional thinking, emotional consciousness, emotional competence, and emotional wisdom (Aleksandrova, 2009; Larina, 2016). N.P. Aleksandrova also mentions that "Emotional intelligence is not a predictor of success, although its presence can serve as a vital tool in achieving the specific results" (p. 73).

The Emotional Intelligence also directs us to our intuition and depicts the contrast between the easy choices and the right choices. Are the easy choices always the right choices? According to (Scott H. Young, Author, Programmer, and Entrepreneur), the hard choices emerge when a specific question has no unique answer or has no answers. According to (Kescia D. Gray, RN, MS, PHN, CHES, owner and the president of GrayKo Clinical Consultants), gathering the relevant information is the fundamental key to the effective decision making. On one hand, too much information can lead to confusion, may misguide us or prevent us from making a decision and following our intuition. On the contrary, relying on a single source of information can lead to inaccuracy, bias, misinterpretations and to severe consequences (Kescia D. Gray). How do we apply the emotional intelligence together with our intuition to obtain the balance between these two dilemmas? How do we find the alpine path that leads us to the summit? 
Kescia D. Gray also recommends to take the following 5 steps prior to making a decision. Identify the goal or problem. What goal do we want to achieve? What problem do we need to solve? Gather the information and weigh your options. Seek diverse information and opinions and then filter or process the information. Consider the consequences. Review the advantages and the disadvantages of all the options. Make the decision. Implement the choice. Evaluating the decision. After you make the decision, expect the unexpected and be flexible to changes and revisions. We will experiences some problems and negative consequences after every decision we make. The fundamental key is to be flexible to the constructive thinking and apply the emotional intelligence for future improvements (Epstein, 1998; Goldman, 1995).

Psychologists and researchers often examine the emotional intelligence together with the connection of its influence on the leadership qualities and the performance. O.V. Belokon (Belokon, 2009) correlated the connection between the emotional intelligence and the business leadership: leaders with high emotional intelligence are capable of stimulating a positive atmosphere in the team and hence motivate the employees to perform their tasks successfully and efficiently.

A.I. Komarova, (Komarova, 2011), conducted cross-cultural studies and discovered a strong correlation between the values of the broader and the individual levels of achievement, benevolence and power (theory of S. Schwartz and V. Bolsky) together with vital fragments of the emotional intelligence such as understanding the management of emotions and the indicators of both the interpersonal and the intrapersonal emotional intelligence due to the cultural specificity.

The primary aim of this section is to apply the emotional intelligence and intuition to design new mini-courses and seminars that promote a positive learning environment and inspire students to learn. For instance, Aivars Vilkaste (director of Autrumlatvijas Tehnologiju Vidusskola in Rezekne, Latvia) offered Michael to conduct some type of a seminar or mini-course for the Academy's high school students. Michael taught a course on "Discrete Mathematics for Computer Science Electronics Engineering” at the Transportation and Sakaru Institute in Riga, Latvia during his spring 2016 sabbatical. The course primarily focused on the pattern recognition and the analysis of patterns. After successfully teaching his Discrete Mathematics course, Michael then decided to design a different version of this course for the high school students and named it "Introduction to Recognition of Patterns and Deciphering of Patterns".

The aim of this mini-course is to render how various patterns can be naturally discovered geometrically by arranging the geometrical configurations and provide the students hands-on practice problems and to write formulas that describe the patterns. During this four-day mini-course, the students get exposed 
to rigorous hands-on practice problems that require vigilant observations of various details such as the types of patterns and how to transition from neighbour to neighbour of each pattern either by addition, multiplication, or by a recursive relation. In addition, the students gained experience in the recognition of piecewise patterns and how these patterns emerge naturally. Despite the fact that the students have seen some of these patterns prior to the mini-course, they did appreciate the depth of knowledge that they gained from the hands-on practice problems that focused on several details that they have not seen before. The students wrote very positive and supportive teaching evaluations and expressed their gratitude to Aivars Vilkaste. Michael and Aivars then decided to conduct this mini-course annually as it welcomed new perspectives for the students and prepares them to focus on meticulous details that they have not encountered before. Michael then decided to write a textbook on "Introduction to Pattern Recognition and Deciphering of Patterns" and plans to use it in the classroom while teaching his mini-course.

\section{Primal Leadership and Innovations}

Transformational Leadership is defined as the leadership that influences positive change to followers and persuades follows to become leaders. On the contrary, Primal Leadership refers to the emotional dimension of leadership and is also the business application of "Emotional Intelligence". The leader's primal task is an emotional task - to articulate a message that resonates with its' followers' emotional reality, with their goals and to transition its' followers in the positive direction. Primal Leadership is the art and science of arousing and focusing the strong positive emotions to the followers and focusing the energy in the specific direction that leads to the accomplishment of goals (Daniel Goldman).

A successful innovator must be a good leader and a good leader must be innovative (Huberman, 1983). A good innovator and leader must be flexible to constructive thinking (Epstein, 1998). Recall that the Primal Leadership focuses on the emotional dimension of leadership, where self-awareness is the most critical feature of the Emotional Intelligence as it lays the foundation for empathy and the remaining three domains. Self-awareness requires the ability to interpret one's emotions, strengths, limitations, values and motives (Bourne, Hanna, Solomon, Smith, \& Sherwood, 2017). H. Weissbach and W. Dax relate the principles of emotional intelligence together with respect, optimism, empathy, and the constructive, supportive and guided criticisms (Weissbach \& Dax, 1998).

To apply the Primal Leadership together with the Emotional Intelligence to design new innovations and practices, it is especially vital to concentrate on the accuracy and the effectiveness of leadership that focuses on the values, strengths and outcomes. Therefore, prior to designing or introducing a new innovation or 
teaching practice, it is pertinent to ask the following questions as shown in the diagram below:

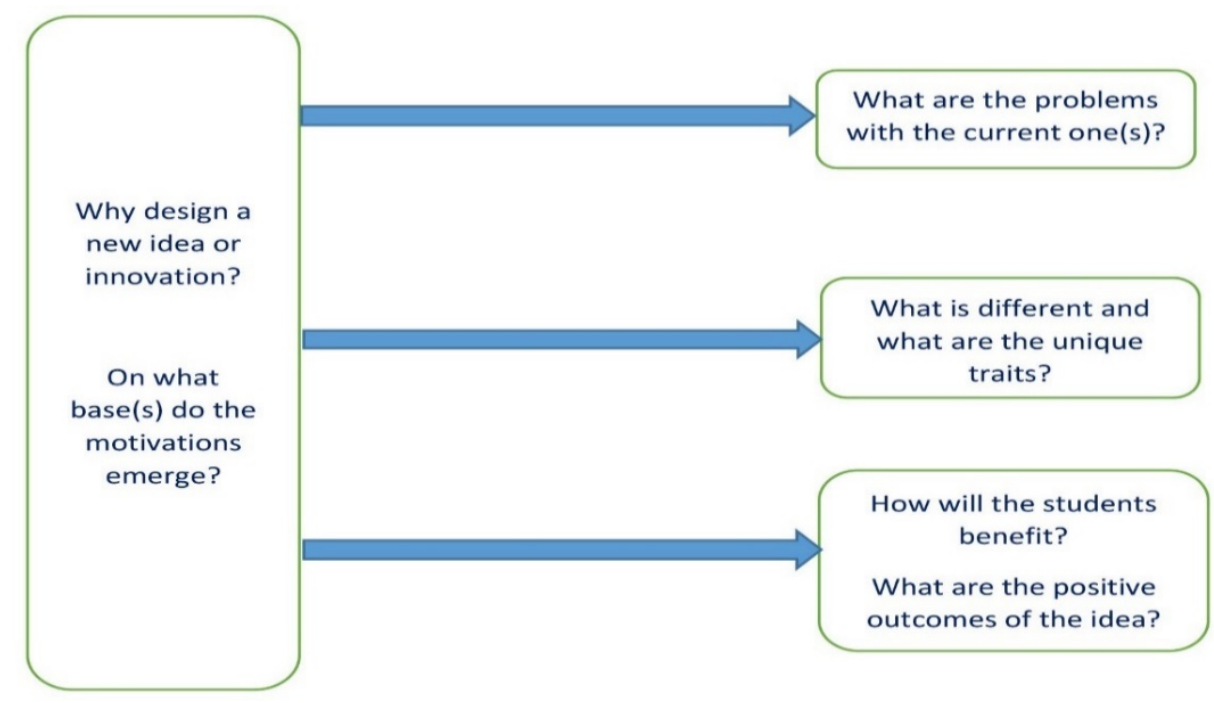

Figure 3 Primal Leadership, design and related questions

While designing a new innovation or practice it is pertinent to establish the base(s) of the motivations and to ask the following questions. What is wrong with the current practice(s) and what problem(s) are we attempting to solve? This question addresses the motivations to design and introduce a new innovation or practice. What unique traits does it offer and render? This question focuses on the uniqueness of the innovation and practice, the differences in comparison to the current ones and the new features. How will the students benefit and what are the positive outcomes? This question leads to the success of the idea, benefits and the positive outcomes. In addition, this is a really pertinent question to consider when asking: why should someone let us implement it? This becomes a vital point of presenting a strong argument in order to promote a new innovation or practice.

It is just as pertinent to apply the Primal Leadership together with the Emotional Intelligence while we are implementing a new innovation and practice. It is especially important to detect the rhythm, the students' progress, participation and the satisfaction during the implementation. The following diagram depicts these essential features to note and consider while introducing and implementing a new practice: 


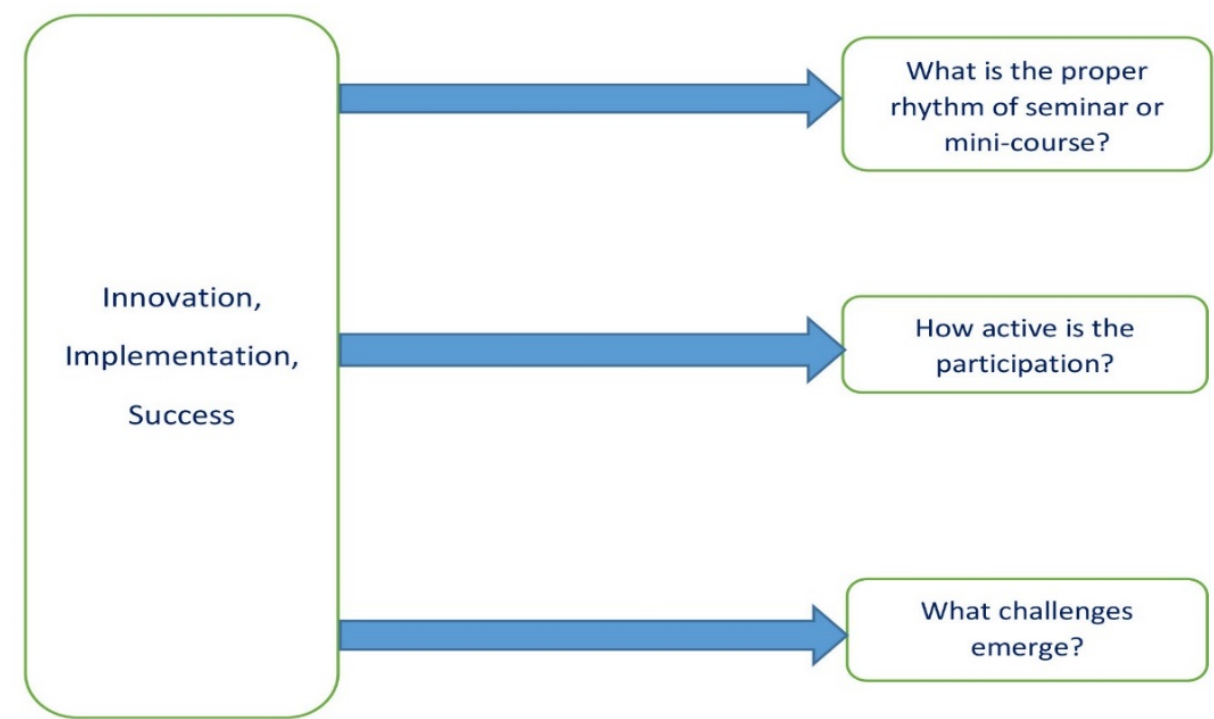

Figure 4 Primal Leadership, implementation and related questions

While implementing a new innovation or practice it is important to observe the following aspects and address the following related questions. What is the proper rhythm or pace? This question focuses on the students' preparation levels and how quickly can they grasp the new principles and coalesce them together with their base knowledge. How active is the students' participation and do they find the seminar or the mini-course interesting and stimulating? This is vital to observe in order to assess how appropriate are the content and the difficulty level. On one hand, if the level is too easy and simple, then the students may be bored and the participation will decline. On the other hand, if the level is too hard, then the students will not understand the content and loose the focus. It is essential to assess the intuitive balance and gradually increase the difficulty level. It is also vital to assess the rate at which the students are grasping the content too. What challenges emerge? We may implement a new practice successfully but never perfectly. For instance, the difficulty level maybe tough and we may transition slightly faster than the natural rate at which students are grasping the concepts. Second of all, the students may have seen the content before but may not be familiar with the symbols, terminology and the content's depth. These are the common problems that are likely to arise during our first implementation (Orlova \& Radin, 2019). The important question to address is not whether the challenges will emerge, but how to handle the challenges effectively as they arise? This is where the emotional intelligence together with the intuition aid as crucial tools that guide in the right direction in assessing the students' value orientations and to the introduction of new themes and practices. 


\section{Conclusions and Future Ideas}

In the previous sections, we shared about various practices by carefully assessing the students' feedback and their value orientations and applying the emotional intelligence together with intuition and the Primal Leadership. These were only the first step of understanding how these three principles serve as a vital guide that lead us to new themes, ideas and practices. The next challenge consists of designing new themes, ideas and practices that relate to the new value orientations as they can change quite rapidly. How do we find the value orientations' and the emotional intelligence path that leads us to new themes, practices and innovations? That is the first challenging task in devising new goals. The next chore is to follow the path that leads us to the successful implementation of innovations and to the meticulous comprehensions of value orientations and emotional intelligence. The final step is to follow the path to future discoveries and innovations. This is where the future innovative journeys commence.

\section{Acknowledgements}

In closing, we would like to take the opportunity to thank our colleagues and students at the Rezekne Technical Academy High School for their support with the new mini-courses that guided us to the new path of ideas and deeper understanding of the value orientations and the emotional intelligence. In addition, we would like to thank the Liepaja University Faculty of Arts and Humanities for their annual support with the Introduction to Photography course that guided to new teaching practices and to more detailed comprehension of students' value orientations and goals. Moreover, we would like to take the opportunity that thank the staff from the Riga Technical University Department of Engineering Economics and the Doctoral School for their support and thorough feedback.

\section{References}

Akhmadieva, R.S., Shagieva, R.V., Ganieva, Y.N., Zulfugarzade, T.E., Ezhov, S.G., \& Komarova, N.M. (2016). Transformation of Students Value Orientations: Behavioral Virtual Models, International Journal of Environmental \& Science Eduation, 11(16), 9144 - 9154.

Aleksandrova, N.P. (2009). The question of the essence of the concept of "emotional intelligence”. Bulletin of the RUDN University. Series: Psychology and Pedagogy, 1, 71-75.

Belokon, O.V. (2008). Emotional Intelligence and the Phenomenon of Leadership: Experiment "Build Together". Psychology. Journal VSE, 5(3), 137 - 144. Retrieved from https://cyberleninka.ru/article/n/emotsionalnyy-intellekt-i-fenomen-liderstvaeksperiment-stroim-vmeste 
Bourne, P.A., Hanna, I., Solomon, T., \& Smith Sherwood, H.A. (2017). Primal Leadership: Realizing the Power of Emotional Intelligence - A Book Review, Crimson Publishers, COJ, 1(2), 46 - 50. DOI:10.31031/COJNH.2017.01.000510

Corley, T. (2010). Rich Habits: The Key to Success and a Happy Future. Minneapolis: Langdon Street Press.

Curran, A., Morris, E., Farrell, P., \& Woods, K. (2007). Emotional Intelligebce and Education: A critical review, Journal of Educational Psychology. International Journal of Experimental Educational Psychology, 27(2), 235-254. DOI:10.1080/01443410601066735

Epstein, S. (1998). Constructive Thinking - The Key to Emotional Intelligence. London: Praeger.

Goldman, D. (1995). Emotional Intelligence. New York: Bantam Books.

Huberman, M. (1983). The role of teacher education in the improvement of educational practice: A linkage model. European Journal of Teacher Education, 6(1), 17-29.

Hussain, M., \& Khan, S. (2016). Students' feedback: An effective tool in teachers' evaluation system. International Journal of Applied Basic Medical Research, 6(3), 178-181.

Komarova, A.I. (2011). Cultural and Psychological features of the relationship of values and emotional intelligence. Ph.D. Thesis in Psychological Sciences and Social Psychology / FGBOU VPO N.G. Chernyshevsky Saratov State University. Saratov.

Larina, A.T. (2016). Emotional Intelligence. ANI: Pedagogy and Psychology, 3(16). Retrieved from https://cyberleninka.ru/article/n/emotsionalnyy-intellekt

Orlova, O., \& Radin, M. (2018). University level teaching styles with high school students and international teaching and learning. Society, Integration, Education. Proceedings of the International Scientific Conference, I, 464-475. DOI: http://dx.doi.org/10.17770/ sie2018vol1.3321

Orlova, O., \& Radin, M. (2019). Balance between leading and following and international pedagogical innovations. The proceedings of the 6th International Scientific Conference "Sociaty, Integraton, Education", 1, 449-459. DOI: http://dx.doi.org/10.17770/ sie2019vol1.3978

Radin, M., \& Riashschenko, V. (2017). Effective pedagogical management as a road to successful international teaching and learning. Forum Scientiae Oeconomia, 5(4), 71-84.

Radomska, J. (2014). Operational Risk associated with the Strategy Implementation. Management, 18(2), 31-43.

Weissbach, H., \& Dax, W. (1998). Emotional Intelligence. Moscow: Lik Press. 